\title{
Pengaruh Karakteristik Individu Dan Karakteristik Pekerjaan Terhadap Kepuasan Kerja Dengan Budaya Organisasi Sebagai Variabel Intervening Pada PT. Perta Arun Gas
}

\author{
Budi Mulia ${ }^{1}$, Marbawi $^{2 *}$, Sapna Biby ${ }^{3}$ \\ ${ }^{123}$ Program Pascasarjana Ilmu Manajemen Universitas Malikussaleh Lhokseumawe \\ Email : budi.181100410011@mhs.unimal.ac.id, marbawi@unimal.ac.id, \\ sapnabiby@unimal.ac.id
}

\begin{abstract}
This study aims to determine how much influence the individual characterstic and job characteristic through organization culture and its impact on job satisfaction of PT. Perta Arun Gas Lhokseumawe City. The data used is the data by distributing questionnaires to 168 employee PT. Perta Arun Gas Lhokseumawe City. To analyze the data, the statistical analysis used structure equation modeling (SEM) and processed with the help of the application Amos. The variables measured include individual characterstic and job characteristic effect toward organization culture of The PT. Perta Arun Gas Lhokseumawe City. Based on the analysis of statistical test is individual characterstic and job characteristic and organization culture affect on the job satisfaction of PT. Perta Arun Gas Lhokseumawe City. The result organization culture variable effect of full mediated on individual characterstic and job characteristic toward to job satisfaction of PT. Perta Arun Gas Lhokseumawe City.
\end{abstract}

Keywords : Individual Characterstic, Job Characteristic, Organization Culture and Job Satisfaction.

\section{A. Pendahuluan}

\section{Latar Belakang}

PT Perta Arun Gas merupakan satu - satunya Perusahaan yang mempunyai fasilitas Regasifikasi di wilayah Aceh dan Sumatera Bagian Utara, disisi yang lain perusahaan juga berada dilokasi geografis dan sangat strategis karena mempunyai jalur transportasi laut yang dapat dengan mudah menerima dan menyalurkan pasokan LNG serta didukung oleh fasilitas dermaga yang sangat memadai. PT Perta Arun Gas memanfaatkan Infrastruktur eks PT Arun NGL yang telah berumur lebih dari 40 tahun untuk menunjang tugas operasional baik regasifikasi maupun treating gas di Lhokseumawe. Persoalan manajemen menjadi perhatian pimpinan PT. PAG Lhokseumawe, baik persoalan kepuasan kerja maupun budaya organisasi.

Kepuasan kerja karyawan PT. PAG merupakan hal yang sangat penting dan mendapat perhatian manajemen, berdasarkan beberapa pendapat para ahli tentang kepuasan kerja dapat disimpulkan kepuasan kerja merupakan bagian dari proses sikap dan perasaan yang dirasakan karyawan PT. Perta Arun Gas dalam organisasinya, kepuasan anggota organisasi dapat dihubungkan dengan kinerja dan hasil kerja mereka, disisi lain persoalan budaya organisasi pada PT. Perta Arun Gas juga penting dibahas untuk meningkatkan kepuasan kerja.

Selain kepuasan kerja karyawan masalah budaya organisasi PT. PAG yang dibangun harus mampu mengikat dan mempengaruhi perilaku individu yang ada dalam organisasi ke arah tujuan organisasi PT. PAG, serta budaya organisasi mampu 
mendorong pelaku organisasi serta organisasi itu sendiri untuk memiliki goals, objectives, persepsi, perasaan, nilai dan kepercayaan, norma-norma bersama yang mempunyai arah yang jelas dan terukur.

Persoalan Karakteristik individu merupakan karakter ataupun perilaku yang melekat pada diri seorang karyawan PT. PAG baik yang bersifat positif maupun negatif. Dengan karakteristik-karakteristik sangat beragam ini, setiap organisasi tentunya dapat memilih seorang karyawan yang mempunyai kriteria yang baik dan karakteristik ini juga harus sesuai dengan apa yang diinginkan organisasi. Menurut Sugijanto (2011), indikator karakteristik individu yaitu: 1) Kemampuan yang sesuai dengan harapan yang diinginkan perusahaan, 2) Nilai yang sesuai dengan harapan yang diinginkan perusahaan, 3) Sikap yang sesuai dengan harapan yang diinginkan perusahaan, 4) Minat yang sesuai dengan harapan yang diinginkan organisasi.

\section{Tujuan dan Manfaat Penelitian}

\section{Tujuan Penelitian}

Berdasarkan pada permasalahan dan fenomena-fenomena yang ada maka tujuan dari penelitian ini adalah sebagai berikut :

1. Untuk mengetahui dan menganalisis pengaruh karakteristik individu terhadap budaya organisasi karyawan PT. Perta Arun Gas Lhokseumawe.

2. Untuk mengetahui dan menganalisis pengaruh karakteristik pekerjaan terhadap budaya organisasi karyawan PT. Perta Arun Gas Lhokseumawe.

3. Untuk mengetahui dan menganalisis pengaruh karakteristik individu terhadap kepuasan kerja karyawan PT. Perta Arun Gas Lhokseumawe.

4. Untuk mengetahui dan menganalisis pengaruh karakteristik pekerjaan terhadap kepuasan kerja karyawan PT. Perta Arun Gas Lhokseumawe.

5. Untuk mengetahui dan menganalisis pengaruh budaya organisasi terhadap kepuasan kerja karyawan PT. Perta Arun Gas Lhokseumawe.

6. Untuk mengetahui dan menganalisis hubungan karakteristik individu terhadap kepuasan kerja melalui budaya organisasi.

7. Untuk mengetahui dan menganalisis hubungan karakteristik pekerjaan terhadap kepeuasan kerja melalui budaya organisasi.

\section{B. Tinjauan Pustaka}

\section{Teori tentang karakteristik individu}

Karakteristik individu menurut George dan Jones (2001), dan Robbins, (2015), karakteristik individu yang tercermin dari kamampuan dan keterampilan, usia, jenis kelamin, status perkawinan, masa kerja, keturunan, lingkungan sosial, pengalaman, dan nilai individu, penempatan karyawan dan personil pada bidang pekerjaan yang sesuai dengan kemampuan dan keterampilan yang dimilikinya akan mengarah pada prestasi dan kepuasan kerja yang tinggi dalam peningkatan kinerja.

\section{Teori tentang karakteristik pekerjaan}

Menurut Gitosudarmo (2013), karakteristik pekerjaan adalah pelaksanaan tugas karyawan yang meliputi wewenang, tanggung jawab serta tugas-tugas yang harus dilakukan, dan juga dapat meningkatan kepuasan yang individu peroleh darikarakteristik pekerjaan yang bersangkutan. Karakteristik pekerjaan merupakan 
dasar bagi produktivitas dan kepuasan kerja karyawan yang dirancang untuk memainkan peranan penting dalam kesuksesan dan kelangsungan hidup perusahaan.(Chandra, Mulyanto, Nugroho, Perhotelan, \& Petra, 2017).

\section{Teori tentang Budaya organisasi}

Budaya Organisasi berfungsi sebagai perekat, pemersatu, identitas, citra, motivator bagi seluruh karyawan dan orang-orang yang ada di dalamnya. Selanjutnya, sistem nilai tersebut diwariskan kepada generasi berikutnya" dan dapat dijadikan acuan perilaku manusia dalam organisasi yang berorientasi pada pencapaian tujuan atau hasil kinerja yang ditetapkan. (Arifin, 2010). Robbin (2013) memberikan rumusan tentang pengertian budaya organisasi adalah nilai-nilai dominan yang didukung oleh organisasi, yang dapat menggambarkan tentang caracara melakukan suatu pekerjaan di tempat tertentu serta asumsi kepercayaan dasar yang terdapat di antara anggota organisasi.

\section{Teori tentang kepuasan kerja}

Menurut Robbins (2015) kepuasan kerja adalah perasaan positif tentang pekerjaan seseorang yang merupakan hasil dari evaluasi karakteristikkarakteristiknya. Luthanns (2011) mendefinisikan kepuasan kerja adalah hasil dari persepsi karyawan mengenai seberapa baik pekerjaan mereka memberikan hal yang dinilai penting. Menurut Mangkunegara (2007), kepuasan kerja adalah suatu perasaan yang menyokong/tidak menyokong diri pegawai yang berhubungan dengan pekerjaannya maupun dengan kondisi dirinya.

\section{Kerangka Konseptual}

Menurut Sekaran (2015) kerangka berfikir adalah dasar pemikiran dari penelitian yang disintesiskan dari fakta-fakta, observasi dan telaah penelitian. Kerangka pikir memuat teori, dalil atau konsep-konsep yang akan dijadikan dasar dalam penelitian. Hubungan antar-antar varibel yang digunakan dalam penelitian ini dapat dilihat pada Gambar 1 dibawah ini :

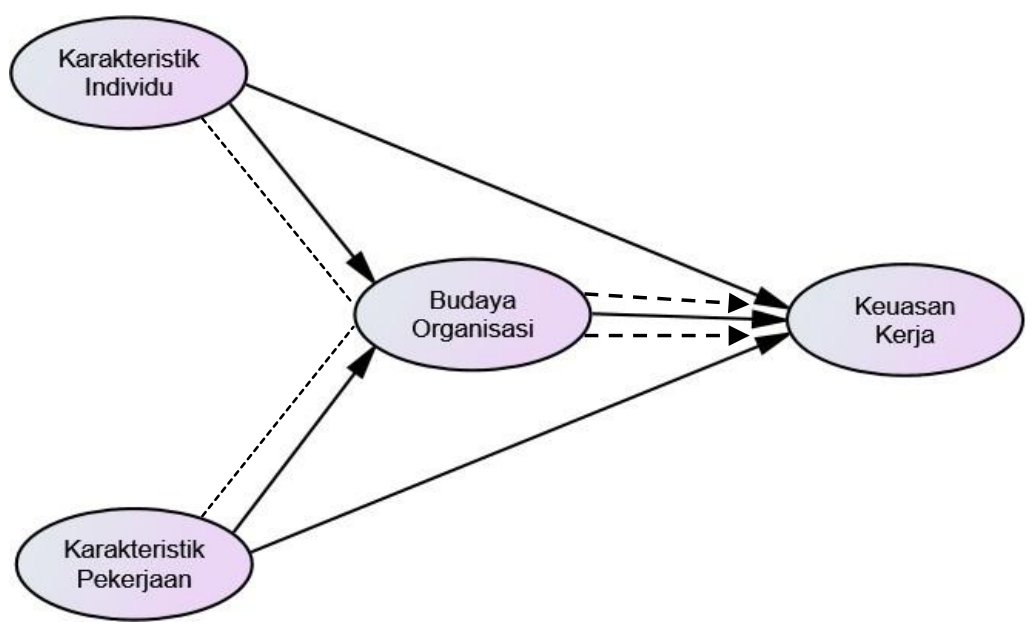

Gambar 1 Kerangka Konseptual 


\section{Hipotesis Penelitian}

Hipotesis adalah suatu pertanyaan sementara atau dugaan yang paling memungkinkan yang masih harus dicari kebenarannya, berdasarkan kerangka konsep yang telag disusun diatas dan penelitian yang dilakukan oleh beberapa peneliti terdahulu maka dapat disusun sebuah hipotesis sebagai berikut :

$\mathrm{H}_{1} \quad=$ Diduga terdapat pengaruh karakteristik individu terhadap budaya organisasi karyawan PT. Perta Arun Gas Lhokseumawe

$\mathrm{H}_{2} \quad=$ Diduga terdapat pengaruh karakteristik pekerjaan terhadap budaya organisasi karyawan PT. Perta Arun Gas Lhokseumawe.

$\mathrm{H}_{3} \quad=$ Diduga terdapat pengaruh karakteristik individu terhadap kepuasan kerja karyawan PT. Perta Arun Gas Lhokseumawe.

$\mathrm{H}_{4} \quad$ = Diduga terdapat pengaruh karakteristik pekerjaan terhadap kepuasan kerja karyawan PT. Perta Arun Gas Lhokseumawe.

$\mathrm{H}_{5} \quad$ = Diduga terdapat pengaruh budaya organisasi terhadap kepuasan kerja pada PT. Perta Arun Gas Lhokseumawe.

$\mathrm{H}_{6} \quad$ = Diduga budaya organisasi memediasi hubungan antara karakteristik individu dengan kepuasan kerja pada PT. Perta Arun Gas Lhokseumawe.

$\mathrm{H}_{7} \quad$ = Diduga budaya organisasi memediasi hubungan antara pkarakteristik pekerjaan dengan kepuasan kerja pada PT. Perta Arun Gas Lhokseumawe.

\section{Metode Penelitian.}

\section{Lokasi Penetian}

Adapun yang menjadi lokasi dalam penelitian ini adalah PT. Perta Arun Gas Lhokseumawe, adapun yang menjadi objek dalam penelitian ini adalah seluruh seluruh karyawan PT. PAG Lhokseumawe.

\section{Populasi dan Sampel Penelitian \\ Populasi}

Populasi dalam penelitian ini merupakan wilayah generalisasi yang terdiri atas obyek/subyek yang mempunyai kualitas dan karakteristik tertentu yang ditetapkan oleh peneliti untuk di pelajari dan kemudian ditarik kesimpulanya, jadi populasi dalam penelitian ini adalah seluruh karyawan PT. PAG Lhokseumawe sebanyak 192 karyawan.

\section{Sampel}

Teknik pengambilan sampel dilakukan dengan metode simple random sampling yaitu pemilihan sampling secara acak sederhana tanpa memperhatikan strata yang ada pada populasi. langkah pertama teknik penarikan sampel ini dilakukan dengan cara menentukan ukuran sampel (sample size) menggunakan metode Maximun Likelihood Estimation (ML) dalam Ghazali (2014) dalam penelitian ini populasi berjumlah 192 maka ukuran sample direkomandasikan dalam mosel SEM antara 100 sampal 200 dan juga dapat diukur 5-10 kali indikator untuk model SEM yaitu 21 indikator x 8 sebesar 168 orang karyawan pada PT. Perta Arun Gas (PAG) Lhokseumawe dan ini sudah memenuhi syarat dalam model penelitian ini. 


\section{Teknik Pengumpulan Data}

Sumber data yang diperlukan dalam penelitian ini, menggunakan angket adalah suatu alat pengumpulan data yang berupa serangkaian pertanyaan yang diajukan tertulis yang diajukan kepada subyek untuk mendapatkan jawaban secara tertulis dari karyawan PT. PAG lhokseumawe tentang analisis karakteristik individu, karakteristik pekerjaan, budaya organisasi dan kepuasan kerja Karyawan PT. PAG Lhokseumawe.

\section{Operasional Variabel}

Tabel 1 Definisi Variabel dan Indikator

\begin{tabular}{|c|c|c|c|c|}
\hline No & Variabel & Definisi Variabel & Indikator & $\begin{array}{l}\text { Skala } \\
\text { Ukur }\end{array}$ \\
\hline 1 & $\begin{array}{l}\text { Karakteristik } \\
\text { Individu } \\
\text { ( KI ) }\end{array}$ & $\begin{array}{l}\text { Ciri-ciri tertentu yang } \\
\text { dimiliki oleh pribadi } \\
\text { personil Polisi Polres } \\
\text { Kota Lhokseumawe. }\end{array}$ & $\begin{array}{l}\text { 1. Kemampuan } \\
\text { 2. Sikap } \\
\text { 3. Nilai } \\
\text { 4. Kepribadian } \\
\text { 5. Pembelajaran } \\
\text { (Marbawi, 2018) }\end{array}$ & Likert \\
\hline 2 & $\begin{array}{l}\text { Karakteristik } \\
\text { Pekerjaan } \\
\quad\left(\mathrm{X}_{2}\right)\end{array}$ & $\begin{array}{l}\text { Kegiatan untuk } \\
\text { meningkatkan kinerja } \\
\text { pegawai pada karyawan } \\
\text { PT. Perta Arun Gas } \\
\text { Lhokseumawe. }\end{array}$ & $\begin{array}{l}\text { 1. Keterampilan } \\
\text { 2. Identitas tugas } \\
\text { 3. Signifikansi tugas } \\
\text { 4. Otonomi } \\
\text { 5. Umpan balik } \\
\text { ((Putri \& Suhaeni, 2014) }\end{array}$ & Likert \\
\hline 3. & $\begin{array}{c}\text { Budaya } \\
\text { Organisasi } \\
\left(\mathrm{Y}_{1}\right)\end{array}$ & $\begin{array}{l}\text { Nilai-nilai sosial yang } \\
\text { dianut dan diyakini } \\
\text { karyawan dalam } \\
\text { berperilaku dalam } \\
\text { organisasipada PT. Perta } \\
\text { Arun Gas Lhokseumawe. }\end{array}$ & $\begin{array}{cl}\text { 1. } & \text { Clean } \\
\text { 2. } & \text { Competitive } \\
\text { 3. } & \text { Confident } \\
\text { 4. Customer Focus } \\
\text { 5. Commercial } \\
\text { 6. Capable } \\
\text { (PT. Perta Arun Gas, 2019) }\end{array}$ & Likert \\
\hline 4. & $\begin{array}{l}\text { Kepuasan Kerja } \\
(\text { KK) }\end{array}$ & $\begin{array}{l}\text { Perasaan } \\
\text { menyenangkan yang } \\
\text { dirasakan dalam } \\
\text { bekerja personil Polres } \\
\text { Kota Lhokseumawe. }\end{array}$ & $\begin{array}{ll}\text { 1. } & \text { Sifat pekerjaan } \\
\text { 2. } & \text { Rekan kerja } \\
\text { 3. } & \text { Supervisor } \\
\text { 4. } & \text { Gaji/upah } \\
\text { 5. Promosi } \\
\text { (Luthans, 2011) }\end{array}$ & Likert \\
\hline
\end{tabular}

\section{Teknik Analisis Data}

Teknik analisis data yang berkaitan dengan analisis sampel untuk penarikan kesimpulan tentang karakteristik populasi dan sample, setelah mengumpulkan data dan informasi dilapangan dari responsen, maka untuk mengelola data dan informasi tersebut, penulis menggunakan metode The Structural Equation Model (SEM) dalam model dan pengujian hipotesis, SEM atau model persamaan struktural dengan sekumpulan teknik-teknik statistik yang pengujian sebuah rangkaian hubungan yang relatif rumit secara simulatan (Ghozali, 2014). Pengertian rumit yang dimaksud adalah model-model simultan yang dibentuk melalui lebih dari satu variabel terikat 
pada saat yang sama berperan sebagai variabel bebas bagi hubungan berjenjang lainnya, dalam penelitian ini digunakan dua macam teknik analisis, yaitu :

1. Analisis konfirmatori (confirmatory factor analysis) pada SEM yang digunakan untuk mengkorfirmatori faktor-faktor yang paling dominan dalam satu kelompok variabel.

2. Regression Weight pada SEM yang digunakan untuk meneliti seberapa besar pengaruh antara variabel-variabel.

\section{Analisis dan Pembahasan}

\section{Gambaran Umum}

Perusahaan didirikan dengan maksud untuk menyelenggarakan usaha di bidang Gas Bumi serta kegiatan usaha lain yang terkait dan atau menunjang kegiatan usaha Gas Bumi di Wilayah Proyek Arun LNG, dengan tujuan untuk memperoleh keuntungan berdasarkan prinsip prinsip pengelolaan perusahaan secara efektif dan efisien. Untuk mencapai maksud dan tujuan tersebut diatas, Perusahaan melakukan kegiatan usaha menyelenggarakan usaha receiving \& regasification terminal/ pembuatan terminal penerimaan dan proses pembentukan gas kembali, termasuk menyelenggarakan kegiatan usaha penunjang lain yang secara langsung maupun tidak langsung menunjang kegiatan usaha tersebut.

PT Perta Arun Gas didirikan berdasarkan Akta No.22 tanggal 18 Maret 2013 yang disahkan oleh Keputusan Menteri Hukum dan HAM Repoblik Indonesia Nio AHU-17317.AH.01.01 ahun 2013 tanggal 18 Maret 2013. Pendirian PT Perta Arun Gas dimulai dengan keputusan Pemegang saham PT Pertamina Gas dan PT Pertagas Niaga tentang pembentukan Badan Usaha untuk proyek Arun LNG Receiving \& Regasification Terminal yang ditandatangani pada tanggal 18 Februari dan 21 Februari 2013. Tanggal 18 Maret 2013 ditetapkan sebagai perusahaan yang bergerak dibidang LNG Receiving \& Regasification Terminal dan usaha usaha lainnya yang menunjang.

\section{E. Hasil Penelitian}

\section{Confirmatori Factor Analisys Konstruk Eksogen}

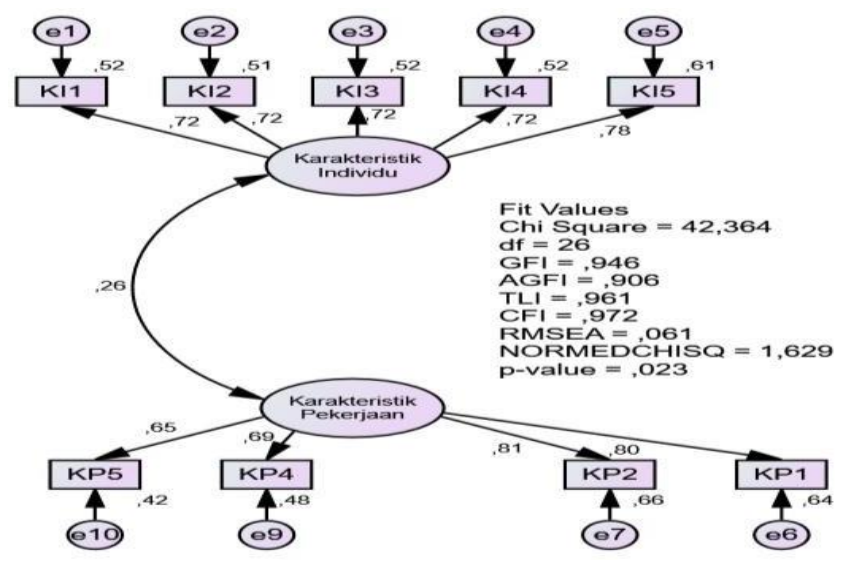

Gambar : 2 CFA Konstruk Eksogen

Sumber : Hasil pengolahan data Amos (2020) 
Hasil dari Confirmatori Factor Analisys untuk kontruk eksogen gambar 2 diatas yang digunakan untuk menguji undimensionalitas indikator pembentuk konstruk laten diatas menunjukkan nilai hasil model sesuai dengan kriteria Goodness of fit, sehingga model dapat diterima.

\section{Confirmatori Factor Analisys Konstruk Endogen}

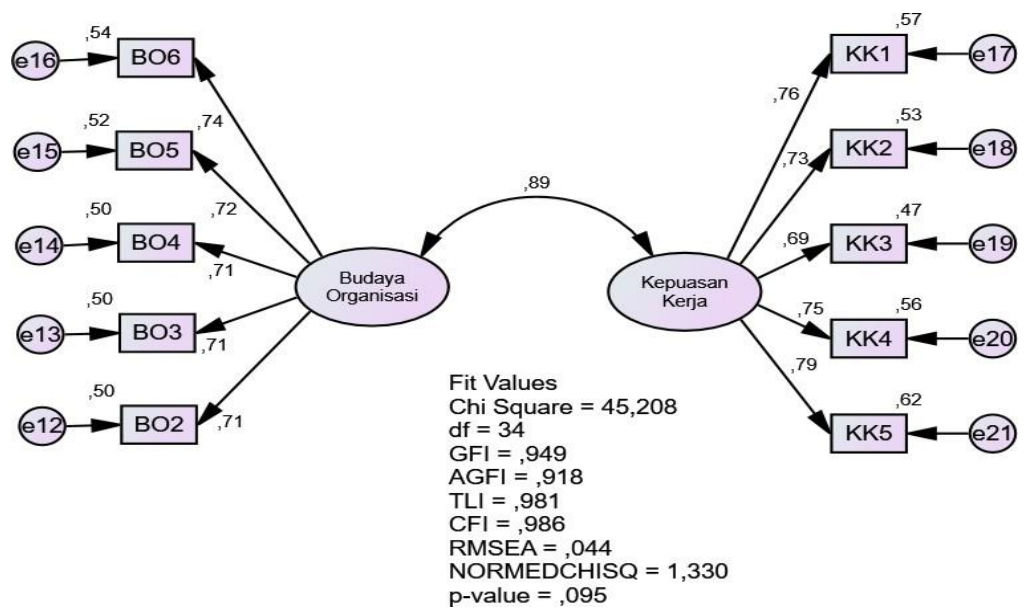

Gambar : 3 CFA Konstruk Endogen

Sumber : Hasil pengolahan data Amos (2020)

Hasil dari Confirmatori Factor Analisys untuk kontruk endogen gambar 3 diatas yang digunakan untuk menguji undimensionalitas indikator pembentuk konstruk laten diatas menunjukkan nilai hasil model sesuai dengan kriteria Goodness of fit, sehingga model dapat diterima.

\section{Structural Equation Modeling (SEM) atau Model Struktural}




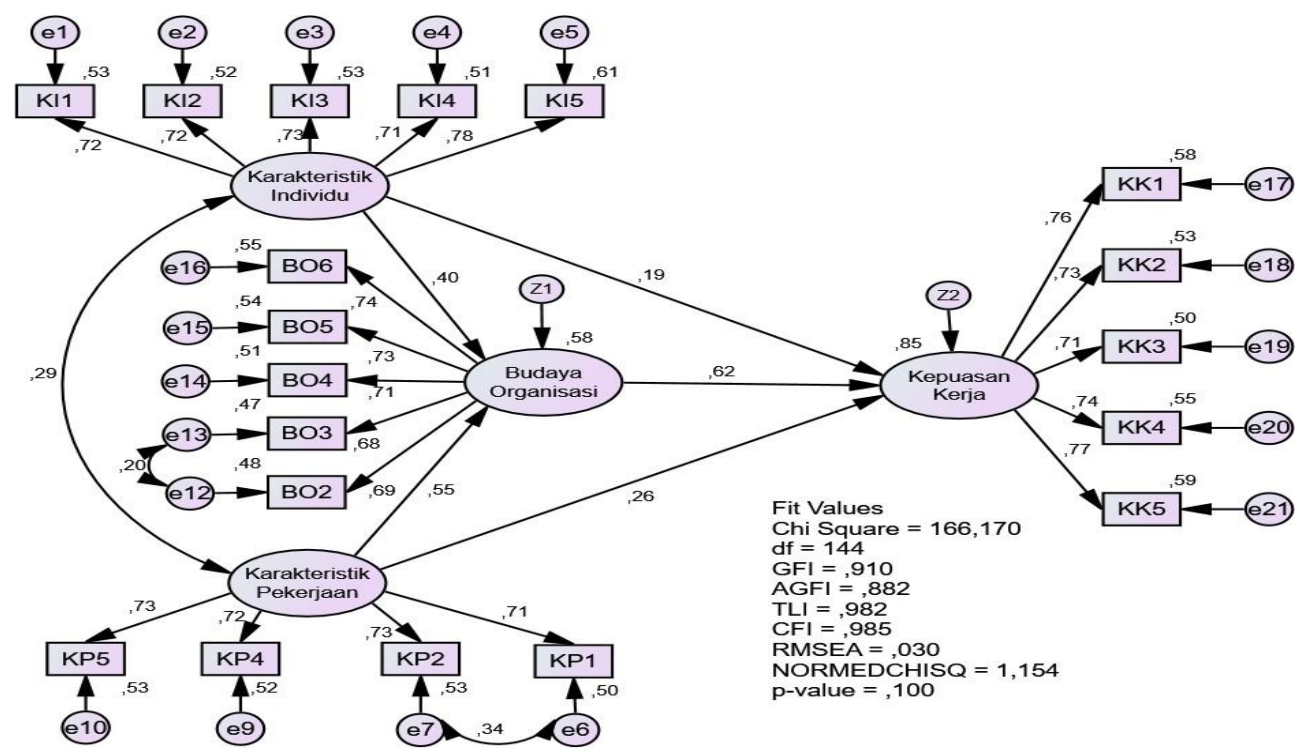

Gambar : 4 Full Model Structural

Sumber : Hasil pengolahan data Amos (2020)

Hasil dari Structural Model untuk kontruk endogen gambar 4 diatas yang digunakan untuk menguji undimensionalitas menunjukkan nilai hasil model sesuai dengan kriteria Goodness of fit, sehingga model dapat diterima.

Tabel 5 : Pengaruh Variabel Eksogen Terhadap Endogen

\begin{tabular}{lrlrrrrr}
\hline \multicolumn{2}{c}{ Regression Weight } & Est. & Std. Est. & S.E. & C.R. & $P$ \\
\hline Budaya_Organisasi & $<---$ & Karakteristik_Individu &, 399 &, 399 &, 086 & 4,660 & $* * *$ \\
Budaya_Organisasi & $<---$ & Karakteristik_Pekerjaan &, 546 &, 520 &, 094 & 5,544 & $* * *$ \\
Kepuasan_Kerja & $<---$ & Budaya_Organisasi &, 619 &, 622 &, 126 & 4,943 & $* * *$ \\
Kepuasan_Kerja & $<---$ & Karakteristik_Individu &, 186 &, 187 &, 075 & 2,487 &, 013 \\
Kepuasan_Kerja & $<---$ & Karakteristik_Pekerjaan &, 256 &, 245 &, 091 & 2,695 &, 007 \\
\hline
\end{tabular}

F. Pembahasan

1. Pengaruh karakteristik individu terhadap Budaya Organisasi

Berdasarkan hasil pengujian hipotesis pertama, terbukti karakteristik individu berpengaruh terhadap budaya organisasi, hasil Analisis membuktikan bahwa nilai

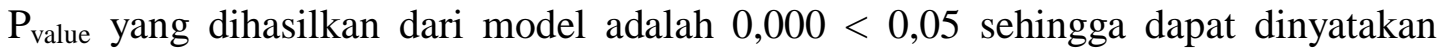
adanya pengaruh yang signifikan karakteristik individu terhadap budaya organisasi karyawan PT. PAG Lhokseumawe. Hal ini berarti bahwa semakin baik meningkat nilai-nilai karakteristik individu sesuai indicator yang di dianalisis, baik sikap, kemampuan dan nilai-nilai yang dianut oleh karyawan PT. PAG Lhokseumawe merupakan sikap yang kepbribadian yang baik sehingga meningkat juga nilai-nilai budaya orgaisasi. Hasil penelitian ini didukung oleh penelitian Lumbanraja (2007), Marbawi (2018), Robbins (2013), Luthans (2011) dan Sopiah (2008) menyimpulkan bahwa karakteristik individu secara parsial berpengaruh terhadap budaya organisasi. 


\section{Pengaruh Karakteristik Pekerjaan Terhadap Budaya Organisasi}

Berdasarkan hasil penelitian terbukti karakteristik pekerjaan memiliki pengaruh positif dan signifikan terhadap budaya organisasi, hasil Analisis membuktikan bahwa nilai $\mathrm{P}_{\text {value }}$ yang dihasilkan dari model $\mathrm{SEM}$ adalah $0,000<0,05$ sehingga dapat dinyatakan adanya pengaruh signifikan karakteristik pekerjaan terhadap budaya organisasi, hal ini berarti bahwa semakin menarik dan menantang karakteristik pekerjaan Karyawan PT. PAG Lhokseumawe maka semakin meningkat nilai-nilai budaya organisasi yang dipahami karyawan. Hasil penelitian ini juga sejalan dengan penelitian kemudian penelitian yang dilakukan oleh Menurut Purnawan (2017) dan Gitosudarmo (2001) karakteristik pekerjaan adalah pelaksanaan tugas karyawan yang meliputi wewenang, indentitas tugas serta tugastugas yang harus dilakukan, dan ototonomi pekerjaan dapat meningkatan kepuasan yang individu dari karakteristik pekerjaan yang bersangkutan dapat meningkatkan nilai-nilai budaya dalam organisasi, Menurut Munandar (2001) dan Simamora (2004), karakteristik pekerjaan merupakan dasar bagi produktivitas organisasi dan kepuasan kerja karyawan yang memainkan peranan penting dalam kesuksesan dan kelangsungan hidup organisasi, sehingga karakteristik pekerjaan dapat meningkatkan nilai -nilai budaya organisasi pada sebuah organisasi.

\section{Pengaruh Karakteristik Individu Terhadap Kepuasan Kerja}

Berdasarkan hasil penelitian terbukti karakteristik individu tidak berpengaruh terhadap kepuasan kerja, hasil analisis membuktikan bahwa nilai $\mathrm{P}$ value yang dihasilkan dari model adalah 0,013>0,05 sehingga dapat dinyatakan tidak terdapat pengaruh karakteristik individu terhadap kepuasan kerja karyawan PT. PAG Lhokseumawe, hal ini berarti bahwa karakteristik individu berdampak terhadap kepuasan kerja karyawan PT. PAG Lhokseumawe, hasil penelitian ini tidak mendukung hasil penelitian yang dikemukakan oleh Lumbanraja (2019), Marbawi (2018), Luthans (2011) dan Robbins (2013) dan Sopiah (2008), Jika hasil penelitian ini dihubungkan dengan dukungan teori yang ada, maka pada dasarnya karakteristik individu secara langsung mempengaruhi kepuasan kerja pada sebuag organisasi.

\section{Pengaruh Karakteristik Pekerjaan Terhadap Kepuasan Kerja}

Berdasarkan hasil penelitian terbukti karakteristik pekerjaan memiliki pengaruh positif dan signifikan terhadap kepuasan kerja, hasil analisis membuktikan bahwa nilai $\mathrm{P}$ value yang dihasilkan dari model adalah $0,007<0,05$ sehingga dapat dinyatakan adanya pengaruh signifikan karakteristik pekerjaan terhadap kepuasan kerja karyawan PT. PAG Lhokseumawe. Hal ini berarti bahwa semakin meningkat meningkat karakteristik pekerjaan maka semakin puas karyawan terhadap organisasi dengan demikian akan terjadi peningkatan pada kepuasan kerja karyawan PT. PAG Lhokseumawe. Penelitian ini mendukung penelitian sebelumnya dimana hasilanalisis membuktikan bahwa ternyata karakteristik pekerjaan berpengaruh terhadap kepuasan kerja, hasil penelitian ini mendukung penelitian Chandra (2017), Prawira (2010), Spector (2008) dan Gomes (2010), jika hasil penelitian ini dihubungkan dengan realita atau kondisi yang sebenarnya pada instansi atau organisasi, maka hasil penelitian tersebut menunjukkan bahwa karakteristik pekerjaan mampu mempengaruhi kepuasan kerja, karena karakteristik pekerjaan yang merupakan bagian dari ketrampilan karyawan, indentifikasi tugas dan otonomi yang diterapkan dalam sebuah organisasi tentunya akan berdampak pada peningkatan kepuasan kerja karyawan. 


\section{Pengaruh Budaya Organisasi Terhadap Kepuasan Kerja}

Berdasarkan hasil penelitian terbukti budaya organisasi memiliki pengaruh positif dan signifikan terhadap kepuasan kerja, hasil analisis membuktikan bahwa nilai $\mathrm{P}$ value yang dihasilkan dari model adalah $0,000<0,05$ sehingga dapat dinyatakan adanya pengaruh signifikan budaya organisasi terhadap kepuasan kerja karyawan PT. PAG Lhokseumawe. Hal ini berarti bahwa semakin baik nilai-nilai budaya organisasi maka kepuasan kerja karyawan terhadap oraganisasi juga akan meningkat. Penelitian ini mendukung hasil mendukung penelitian Marbawi (2018), Noor (2014), Luthan (2011), Sopiah (2008) dan Lumbanraja (2007), kondisi ini dapat dijelaskan sebagai berikut seorang pegawai yang merasa puas terhadap pekerjaan, kesempatan promosi, supervisi, rekan sekerja serta imbalan yang layak, maka kondisi tersebut maka akan meningkakatan kepuasan kerjanya terhadap pekerjaan dan kinerja organisasi tentunga akan meningkat searah peningkatan nilai-nilai budaya organisasi.

\section{Budaya Organisasi Memediasi Hubungan Karakteristik Individu Terhadap Kepuasan Kerja}

Hasil uji effek mediasi yang dilakukan dengan metode sobel test an interactive calculation tool for mediation tests dimana nilai test statistic diperoleh nilai sebesar C'sebesar 0,247 nilai p-value sebesar 0,371>0,05 sedangkan jalur C sebesar 0,780 p-value sebesar $0,013<0,05$. Berdasarkan hasil analisis nilai koefesien dan nilai $\mathrm{P}$ value terjadi penurunan nilai koefisien dari $\mathrm{C}$ ke $\mathrm{C}$ ' dengan demikian dapat disimpulkan budaya organisasi memediasi secara penuh (full mediation) hubungan antara karakteristik individu dengan kepuasan kerja karyawan PT. PAG Lhokseumawe, dari hasil perhitungan dan analisis data disimpulkan bahwa budaya organisasi berfungsi sebagai variabel memediasi penuh hubungan karakteristik individu terhadap kepuasan kerja.

\section{Budaya Organisasi Memediasi Hubungan Karakteristik Pekerjaan Terhadap Kepuasan Kerja}

Hasil uji effek mediasi yang dilakukan dengan metode sobel test an interactive calculation tool for mediation tests dimana nilai test statistic diperoleh nilai sebesar C'sebesar 0,338 nilai p-value sebesar 0,193>0,05 sedangkan jalur C sebesar 0,161 p-value sebesar 0,007 <0,05. Berdasarkan hasil analisis nilai

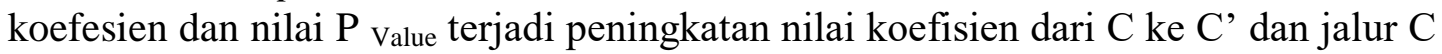
signifikan menjadi C'tidak signifikan dengan demikian dapat disimpulkan budaya organisasi memediasi secara penuh (full mediation) hubungan antara karakteristik pekerjaan dengan kepuasan kerja karyawan PT. PAG Lhokseumawe, dari hasil perhitungan dan analisis data disimpulkan bahwa budaya organisasi berfungsi sebagai variabel memediasi penuh hubungan karakteristik pekerjaan terhadap kepuasan kerja.

\section{G. Kesimpulan}

Berdasarkan analisis data dan pembahasan beberapa hal dapat disimpulkan sebagai berikut : 
1. Karakteristik individu berpengaruh signifikan terhadap budaya organisasi karyawan PT. PAG Lhokseumawe, artinya karakteristik individu karyawan selama ini dapat mendukung untuk meningkatkan nilai-nilai budaya organisasi.

2. Karakteristik pekerjaan berpengaruh positif dan signifikan terhadap budaya organisasi karyawan PT. PAG Lhokseumawe, artinya karakteristik pekerjaan yang selama ini diterapkan berdampak langsung terhadap peningkatan budaya organisasi pada PT. PAG Lhokseumawe.

3. Karakteristik Individu berpengaruh positif dan signifikan terhadap kepuasan kerja karyawan PT. PAG Lhokseumawe, artinya karakteristik individu karyawan selama ini dan diterapkan pada perusahaan dapat berpengaruh langsung terhadap peningkatan kepuasan kerja karyawan PT. PAG Lhokseumawe.

4. Karakteristik pekerjaan berpengaruh terhadap kepuasan kerja karyawan PT. PAG Lhokseumawe, artinya karakteristik pekerjaan dapat meningkatkan kepuasan kerja karyawan PT. PAG Lhokseumawe.

5. Budaya organisasi berpengaruh positif dan signifikan terhadap kepuasan kerja karyawan PT. PAG Lhokseumawe, hal ini bermakna nilai-nilai budaya organisasi karyawan selama ini berdampak terhadap peningkatkan kepuasan kerja karyawan PT. PAG Lhokseumawe.

6. Budaya organisasi berfungsi sebagai variable memediasi secara parsial (parsial mediasi) hubungan karakteristik individu dengan kepuasan kerja karyawan PT. PAG Lhokseumawe, artinya budaya organisasi merupakan satu-satunya variable yang dapat memediasi dalam model penelitian ini.

7. Budaya organisasi berfungsi sebagai variable memediasi secara parsial (parsial mediasi) hubungan karakteristik pekerjaan dengan kepuasan kerja karyawan PT. PAG Lhokseumawe, artinya budaya organisasi merupakan satu-satunya variable yang dapat memediasi dalam model penelitian ini.

\section{Daftar Pustaka}

Arifin, N. (2010). Analisis Budaya Organisasional Terhadap Komitmen Kerja Karyawan Dalam Peningkatan Kinerja Organisasional Karyawana Pada Koperasi Bmt Di Kecamatan Jepara- Noor Arifin. Jurnal Ekonomi \& Pendidikan, Volume 8 N(STIENU Jepara), 173-192.

Bangun, Wilson. Manajemen Sumber Daya Manusia, Jakarta : Erlangga, 2012. Brasmasari, Ida Ayu dan Suprayetno, Agus., "Pengaruh Motivasi Kerja,

Kepemimpinan dan Budaya Organisasi Terhadap Kepuasan Kerja Karyawan Serta Dampaknyaada Kinerja Perusahaan.” Studi kasus pada PT. Pei Hai International Witama Indonesia. Jurnal, Manajemen dan Kewirausahaan, Vol. 10. Nomor. 2, 2008.

Baron and Kenny (1986), Asymptotic confidence intervals for indirect effect in S.Leinhard (Ed).

Ferdinand, Augusty, Metode Penelitian Manajen, Podoman Penelitian Skripsi, Tesis, dan Desertas Ilmu Manajemen, Edisi kelima, Semarang : BP-UNDIP,. 2014.

Garay, H.D.V. (2006). Kinerja Extra-Role dan Kebijakan Kompensasi. Sinergi Kajian Bisnis dan Manajemen, Vol. 8, No. 1, 33-42. 
Ghozali, Imam,. Konsep dan Aplikasi Dengan Progran AMOS 22.0, Cetakan ke 6, Semarang : Badan Penerbit Universitas Diponegoro, 2014,

Hasibuan, H. Melayu S.P., Manajemen Sumber Daya Manusia, Jakarta : PT. Bumi Aksara, 2009.

Irawan, Indra (2012). Pengaruh Karakteristik Individu dan Karakteristik Kerja Terhadap Organization Citizenship Behavior dengan Kepuasan Kerja sebagai variabel Mediator Pada Event Organizer Di Surabaya, Kajian Ilmiah Mahasiswa Manajemen Vol 1, No 2,

Ivancevich, John M, Konopaske dan Matteson. (2006). Perilaku Dan Manajemen Organisasi. Edisi 7 Jilid 2. Alih bahasa: Dharma Yuwono. Jakarta: Erlangga.

Koesmono H. Teman., (2005). Pengaruh Budaya Organisasi Terhadap Motivasi dan Kepuasan Kerja Serta Kinerja Karyawan Pada Sub Sektor Industri Pengelahan Kayu Ekspor di Jawa Timur, Desertasi Universitas Airlangga, Surabaya.

Lok, Peter and John Crawford., (2003). The Effect of Organizational Culture and Leadership Style on Job Satisfaction and Organizational Commitment, ACross-national comparison, Jornal of Management Development; 2004; 3/4; ABI/INFORM Research, Pg 321.

Lumbanraja, Prihatin., (2007). Desertasi: Pengaruh Kateristik Individu, Gaya Kepemimpinan dan Budaya Organisasi Terhadap Kepuasan Kerja dan Komitmen Organisasi, Program Pascasarjana, Universitas Brawijaya Malang. Luthans, Fred., (2011). Organizational Behavior, Tweltf Edition, McGrawHill Companies Inc. New York.

Mangkunegara, A.A. Anwar Prabu., (2007). Evaluasi kinerja SDM, Rafika Aditama, Bandung.

Marbawi, (2017). The influence of individual characteristics and transformational leadership on job satisfaction and performance of employee in Bank Aceh Syaria, Proceding EBIC Universitas Sumatera Utara.

Munandar, A.S., Bertina Sjabaddhyni dan Rufus Patty Wutun., (2004). Peran Budaya Organisasi Dalam Peningkatam Unjuk Kerja Perusahaan, Depok. Penerbit PIO Fakultas Psikologi, Universitas Indonesia, Jakarta.

Mas'ud, Fuad., (2004). Survai Diagnosis Organisasiaonal : Konsep dan Aplikasi. Banan Penerbit Universitas Diponegoro, Semarang.

Muzakir (2019) Analisis Pengaruh Kepuasan Kerja Dan Motivasi Kerja Terhadap Kinerja Perawat Dengan Komitmen Organisasi Sebagai Variabel Intervening Pada Rumah Sakit Umum Cut Meutia Aceh Utara, Tesis Program Pasca Sarjana Ilmu Manajemen Fakultas Ekonomi Dan Bisnis, Universitas Malikussaleh Lhokseumawe.

Noor, Juliansyah., (2013). "Penelitian Manajemen" Tinjauan Filosofis dan Praktis Edisi Pertama, Prenadamedia Group, Jakarta.

Ndraha, Taliziduhu., (2003). Budaya Organisasi, Cetakan Kedua, Penerbit Rineka Cipta, Jakarta.

Nimran, Umar., (2004). Perilaku Organisasi, Cetakan ketiga, CV. Citra Media, Surabaya. 
Noor, Juliansyah., (2013). "Penelitian Manajemen" Tinjauan Filosofis dan Praktis Edisi Pertama, Prenadamedia Group, Jakarta.

Sekaran, Uma., (2015). Research Methods For Busines. Metodologi Penelitian Untuk Bisnis, penerbit Salemba empat, Jakarta.

Majid, Abdul (2019) Faktor Penentu Kepuasan Kerja Personil TNI Konim 0103 Aceh Utara, Tesis Program Pasca Sarjana Ilmu Manajemen Fakultas Ekonomi Dan Bisnis, Universitas Malikussaleh Lhokseumawe.

Preacher, K. J., \& Hayes, A. F. (2004). SPSS and SAS procedures for estimating indirect effects in simple mediation models. Behavior Research Methods, Instrumentsand Computers, 36,717 731 .

Preacher, K. J., \& Hayes, A. F. (2008a). Asymptotic and resampling strategies for assessing and comparing indirect effects in multiple mediator models. Behavior Research Methods, 40,879 891.

Putri, I. S. S., \& Suhaeni, T. (2014). Pengaruh Karakteristik Pekerjaan Terhadap Kepuasan Kerja Karyawan Pada CV Fruity Indonesia. Jurnal Sigma-Mu, 6, $37-48$.

Rachmawati, K. V., Mulwaningsih, T., \& Susilowati, T. (2019). Karakteristik Pekerjaan dan Karakteristik Individu Terhadap Kepuasan Kerja Pegawai. Journal of Chemical Information and Modeling, 53(9), 1689-1699. https://doi.org/10.1017/CBO9781107415324.004

Rivai, Veithzal dan E.J. Sagala., (2011). Manajemen Sumber Daya Manusia untuk Perusahaan: dari Teori Ke Praktik, Edisi Pertama, Penerbit PT. Raja Grafindo Persada, Jakarta.

Robbins, Stephen P dan Timothy A. Judge., (2011). Organizational Behavior, Prentice Hall Inc., New Jersey. 